\title{
How does Inequality Hamper Subjective Well-being? The Role of Fairness
}

\section{Zeynep B. Ugur ${ }^{1}$ (D)}

Accepted: 2 May 2021 / Published online: 15 May 2021

(c) The Author(s), under exclusive licence to Springer Nature B.V. 2021

\begin{abstract}
In this study, we aim at clarifying the role of economic inequality on the subjective well-being of individuals. For this purpose, we use more than 180,000 individuals from 51 countries in the most recent five waves (1990-2014) of the World Values Survey. We observe a significant tradeoff between life satisfaction, happiness and the Gini coefficient. Also, inequality is negatively associated with life satisfaction and happiness for lowerincome groups as well as higher-income groups. Interestingly, our data also shows large scale embracement of inequality in self-reported attitudes as even almost half (49\%) of the lower-income group support the statement that some inequality is necessary for sustaining individual effort. Perceived freedom, and perceived social mobility partially mediates the relationship between the Gini coefficient and subjective wellbeing indicators. Yet, there remains a substantial negative effect of inequality on subjective well-being. Nevertheless, when individuals' perception of fairness is included, the effect of inequality disappears for both higher-income and lower-income groups. Overall, our findings suggest that people are bothered by inequality primarily due to fairness concerns.
\end{abstract}

Keywords Inequality $\cdot$ Fairness $\cdot$ Happiness $\cdot$ Life satisfaction

JEL Classification D63 · I31

\section{Introduction}

Recently, many famous people such as Barack Obama, even people known for their wealth, such as Mark Zuckerberg and Warren Buffet, publicly expressed their dislike about income inequality. Indeed, many studies show experimental evidence that an average person has a distaste for inequality (e.g., Fehr and Schmidt (1999); Dawes et al. (2007); Xiao and

They have set me up here so high that I can see all the ugliness and all the misery of my city, and though my heart is made of lead yet I cannot choose but weep (from The Happy Prince by Oscar Wilde).

Zeynep B. Ugur

zeynep.ugur@asbu.edu.tr

1 Department of Economics, Social Sciences University of Ankara, Hukumet Meydanı No:2 Ulus, Ankara, Turkey 
Bicchieri (2010); Yang et al. (2016)). This trait is pervasive in a wide range of countries (Kiatpongsan \& Norton, 2014) and prevalent even among six-year-old children (Shaw \& Olson, 2012).

There are several social and psychological reasons for economic inequality to lower the well-being of economically disadvantaged groups. Other's relative advantage is found to lower the life satisfaction of the disadvantaged (Ferrer-i-Carbonell, 2005; Luttmer, 2005).

On the other hand, inequality may be beneficial for the upper-income group as they gain in terms of social comparison. Nevertheless, Alesina et al. (2004) show that inequality reduces the happiness of the wealthy in the USA. Norton and Ariely (2011) shows that wealthy people in the USA desire a more equal distribution of wealth than currently exists. These findings suggest that there can be some underlying reasons for inequality to lower wellbeing beyond self-interest.

Many normative theories demand some form of equality such as economic equality, equal resources, or equal opportunities (Sen, 1992). The overarching theme in all these different equality considerations seems to be fairness or justice. For example, well-known philosopher John Rawls (1971) argues for enhancing the position of the least advantaged groups in a society ${ }^{1}$ for the sake of fairness. Therefore, living in a high inequality setting might trigger feelings of unfairness and thereby lower wellbeing. On the other hand, many empirical findings suggest that inequality, when it is perceived as a result of a mere reflection of differences in merit and through a fair allocation mechanism, is tolerable. Firstly, research results indicate that people have a preference for some inequality, too (Kiatpongsan \& Norton, 2014; Norton \& Ariely, 2011). For the USA, Eriksson and Simpson (2012) report the ideal wealth ratio of the bottom quintile to top quintile to be 1:50, which is much higher than 1:4 ratio reported by Norton and Ariely (2011) mainly due to anchoring effects in the latter study. Fehr and Schmidt (1999)'s seminal paper explains that fairness requires equity, which is equivalent to equality in the lab experiments as people are randomly allocated different roles. After examining findings on inequality aversion and fairness concerns, Starmans et al. (2017) suggests that in the studies that find an egalitarian allocation of resources, there is no difference in merit or need between subjects that would justify the unequal distribution of resources. Therefore, this study concludes that what matters is not inequality per se, but unfairness. Shaw and Olson (2014) show that children would prefer inequality if it is through an impartial procedure such as the random choice of a fair spinner rather than throwing resources to trash. Therefore, the effect of inequality might change depending on how fair the individual perceives the society.

Also, social mobility may confound the effect of inequality on subjective well-being. In this regard, Hirschman's Tunnel Effect Hypothesis suggests that a person may see others' upward mobility as positive to a certain extent as it can provide a positive signal about the prospects of the person from a self-interest point of view (Hirschman \& Rothschild, 1973). If people think that hard work brings a better life, they may tolerate higher inequality, believing that one day the poor can escape poverty with hard work (Alesina et al., 2004; Benabou \& Ok, 2001). However, rather than actual social mobility, perceived social mobility is likely to influence the preferences for inequality.

In Amartya Sen (1999)'s approach, freedom is the ultimate end in itself. Then, if people in a country are feeling free, they might approach the inequality level of that country as socially acceptable (Michels \& De Graaf, 2010; Putnam, 2000). On the other hand, high

\footnotetext{
1 Harsanyi (1980) claims that Rawl's veil of ignorance would lead to average utility maximization rather than maximizing the worst-case scenarios.
} 
inequality in a country can be a means for constraining freedom of individuals. Deaton (2013) gives a historical account about how inequalities can be used to reduce people's various freedoms by rent-seeking processes. Moreover, Acemoglu and Robinson (2000) argues that expansion of political freedoms reduced inequality abruptly in Western societies in nineteenth century. These considerations suggest that freedom may mediate the impact of inequality on wellbeing.

In this study, we firstly examine the impact of income inequality on subjective wellbeing for more than 180,000 individuals coming from 51 countries surveyed between 1990 and 2014. Secondly, we complement regression analysis with individuals' self-reports about attitudes towards inequality. Thirdly, to reconcile apparently contradictory findings, we focus on the underlying reasons for the negative relationship between inequality and wellbeing by examining on the role of freedom, social mobility and fairness perception.

In the literature, the first study finds lower happiness in a high inequality community between two very similar communities in Israel (Morawetz et al., 1977). Alesina et al. (2004) find that individuals are less satisfied with life in Europe and less happy in the USA when inequality is high in a country (state for the USA) fixed effects model. Oishi and Kesebir (2015) show that among 34 countries, economic growth was not associated with higher happiness when income inequality also grows. This study uses aggregate happiness scores for each country but differences between countries are treated as the component of the error term. One consistent finding to emerge from Ferrer-i-Carbonell and Ramos (2014)'s literature review is that people both in Western and non-Western settings have a lower subjective well-being when there is higher income inequality in the places they reside. Nevertheless, previous studies did not study in detail the possible mechanisms through which inequality hurts. Ferrer-i-Carbonell and Ramos (2014) mention that there are important caveats about the negative association between inequality and happiness in non-Western countries because those studies did not control for country fixed effects. However, inequality is very much linked to country-specific institutions and historical circumstances (Piketty \& Saez, 2014). Thus, to account for cultural differences between countries, country fixed effects models are necessary.

This study extends prior research on the effect of inequality on subjective well-being in several ways. First, we replicate the previous findings by showing a statistically significant negative relationship between inequality and life satisfaction and happiness in country fixed effects specification overall, and for lower as well as higher-income groups for a much broader set of countries. Secondly, we differentiate between the effect of inequality on life satisfaction, which captures a cognitive evaluation of one's life and on happiness, which measures emotional wellbeing in daily experiences. We find that inequality is more detrimental to life satisfaction than to happiness. Thirdly, utilizing people's self-reports from 51 countries, we show that preference for some inequality is a worldwide phenomenon. Our primary contribution comes from showing that, social mobility and freedom perception partially mediates the inequality-SWB relationship. That is, the negative relationship between the Gini coefficient and subjective wellbeing measures survives after taking into account these. Nevertheless, when individuals' perception of fairness is included, the effect of inequality disappears for both higher-income and lower-income groups. Overall, our findings suggest that people are bothered by inequality due to primarily fairness concerns.

This study is especially important as inequality has been on the rise in many countries, both known to be equal such as Sweden and Germany and unequal such as United States (OECD, 2011, 2015; Piketty \& Saez, 2014). Our results speak to increasing social concerns about the repercussions of rising inequality. 


\section{Materials and Methods}

To study the relationship between individuals well-being and the degree of inequality in the society they are living, we use the following equation,

$$
S W B_{i, c, t}=I N E_{c, t} \alpha+X_{i, c, t} \beta+Y_{c, t} \gamma+\theta_{c}+\varepsilon_{i, c, t}
$$

where $S W B$ represents subjective well-being indicators such as happiness or life satisfaction scores for individual $i$, living in country $c$ in year $t$. INE denotes the inequality level of each country $c$ at time $\mathrm{t}$, and $X$ is a vector of other control variables that are individual level. They are chosen based on previous findings in the literature that has been found to affect the individual's subjective well-being. An in-depth explanation of the control variables is in the following section.

For identifying the effect of inequality on subjective well-being correctly, the unobserved characteristics that can affect subjective well-being should be uncorrelated with the Gini coefficient. If some countries have happier populations for some historical reasons as well as lower inequality, the observed relationship might be stemming from some country-specific properties. To address this concern, we utilize country fixed effects specification, which requires observing the same country more than once. In Eq. $1, \theta_{c}$ denotes for a vector of dummy variables for each country in the sample. Also, the observed relationship between inequality and subjective well-being may also be confounded by time-varying macroeconomic changes. In our econometric model, $Y$ refers to a vector of country level control variables such as GDP per capita. In some specifications, total unemployment level, unemployment level for both genders and country level educational attainment is also added.

We confined our sample to the countries that have experienced economic growth and discarded Cyprus whose economy declined in the survey years. The reason is that a large literature (e.g. Kahneman and Tversky (1979)) finds that losses loom larger than gains (loss aversion). According to notion of loss aversion, when economy contracts the effects on wellbeing might be much larger than the effect of economic expansion.

We make use of the cross-country and time variation in inequality to be able to estimate $\alpha$. Moreover, economic inequality may affect higher income and lower income groups not in the same way and it can have different implications in different cultural contexts, we study its impact by restricting the sample to different income and cultural groups.

To uncover the underlying mechanisms of the relationship between income inequality and subjective wellbeing, we study whether perceived freedom, social mobility and fairness mediates this relationship as shown graphically in Fig. 1.

\subsection{Data}

This study uses individual-level data from the World Values Survey (WVS)'s most recent five waves conducted between the years 1990 and 2014. WVS is based on a representative sample from each country that participated in the survey.

WVS covers many topics, including happiness, life satisfaction, attitudes toward income equality, and many socioeconomic status indicators. Happiness was measured using the answers to the following question: "Taking all things together, would you say you are happy?" ranging from 1 "not at all happy" to 4 "very happy." Life satisfaction was measured using the answers to the following question: "All things considered, how satisfied are you with your life as a whole these days?" ranging from 1 "dissatisfied" to 10 "satisfied." 
Fig. 1 Graphical sketch of the inequality and SWB relationship

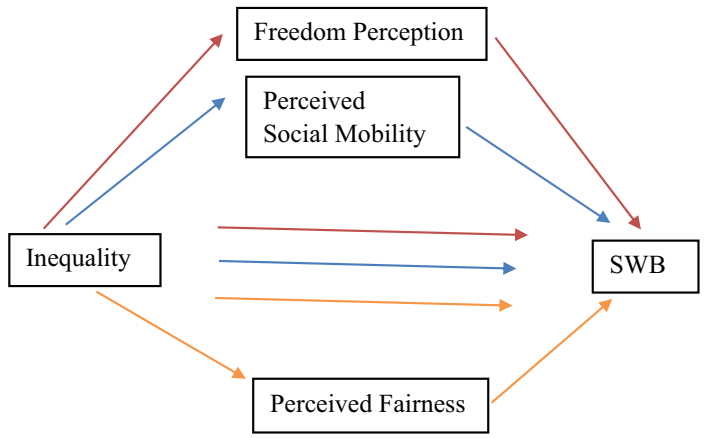

Attitudes toward income equality were measured using the self-reported placement on a ten-point scale, which ranges from 1 "Incomes should be made more equal" to 10 "We need larger income differences as incentives for individual effort."

As control variables, we use gender, age, country of residence, last completed education level, marital status (categories: married/living with partner, divorced/separated, widowed, single), employment status (categories: full-time employed, part-time employed, selfemployed, retired, house-maker, student, unemployed, other employment status). Income is measured with a subjective placement on a ten-point economic ladder scale based on total household income. ${ }^{2}$

As it is the most common and largely available measure of economic inequality in a country, we use the Gini coefficient from the World Bank database. The Gini coefficient measures the degree of deviation from perfect equality, and it ranges from 0 (total equality) to 1 (total inequality).

Economic development is measured as GDP per capita, which is obtained from the World Bank database. Similarly, the total unemployment rate and the unemployment rate for both genders are obtained from the World Bank database. ${ }^{3}$

For measuring the perceived fairness, the following question is used "Do you think most people try to take advantage of you or they try to be fair." In some survey years, two options were possible as answer categories (Would take advantage- Try to be fair), and in some survey years, the ten-point Likert scale is used where 1 means "Would take advantage" and 10 means "Try to be fair."

For measuring the freedom level of the country, Freedom House's country-level evaluation is used. Freedom House evaluates countries' liberties in 3 categories, which are as follows: not free, partly free, and free. Also, individuals' assessment of freedom in her/ his own life is obtained from the following question "Using this scale where 1 means "no choice at all" and 10 means "a great deal of choice" please indicate how much freedom of choice and control you feel you have over the way your life turns out:"

\footnotetext{
2 The wording of the question is as follows: "On this card is an income scale on which 1 indicates the lowest income group and 10 the highest income group in your country. We would like to know in what group your household is. Please, specify the appropriate number, counting all wages, salaries, pensions and other incomes that come in".

${ }^{3}$ In that dataset, national estimates were also available. However, there were many missing values in national estimates. Therefore, ILO's estimates are used.
} 


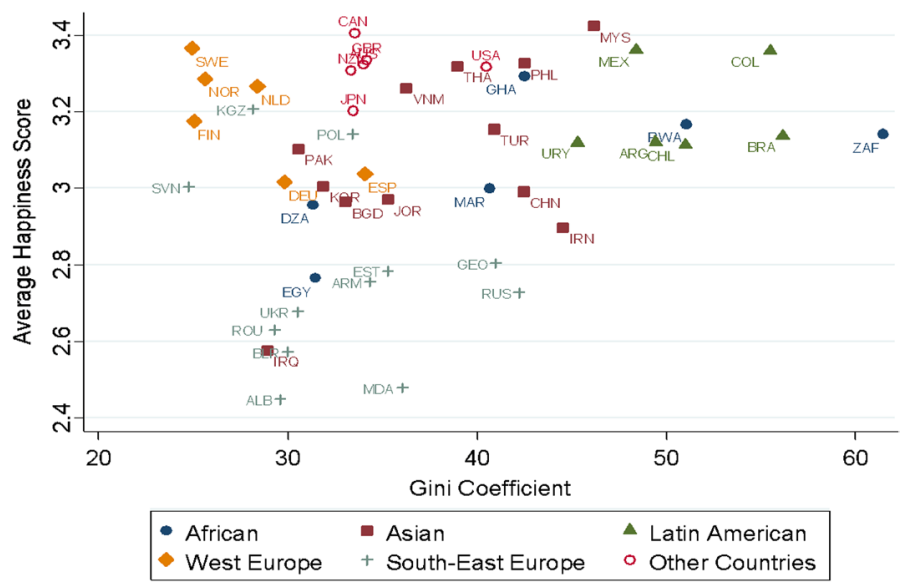

Fig. 2 Inequality and happiness relationship

For measuring mobility perceptions, respondents' degree of agreeing with the following statements are used "In the long run, hard work usually brings a better life" vs. "Hard work doesn't generally bring success_-it's more a matter of luck and connections" where 1 means the respondents believe social mobility and 10 means the respondents do not believe the possibility of social mobility at all.

Cyprus is dropped from the sample as its GDP per capita had declined over time in which they were observed in the World Values Survey. Bosnia, India, Taiwan, Hong Kong, Indonesia, Puerto Rico, Singapore, Switzerland, Serbia, Bulgaria, Czech Republic, Zimbabwe, and Venezuela and Macedonia are dropped from the sample as their Gini coefficient was not available in the survey years at least twice in World Bank Dataset. We obtained Gini coefficients of Finland, Great Britain, Germany, Norway, Sweden, Japan, and New Zealand for some years from the OECD dataset website as they were not available in the World Bank dataset.

In order to account for cultural differences between countries and changes over time, country and time fixed effects models will be run. Therefore, we restrict our sample to the remaining 51 countries, which have been observed at least twice in the World Values Survey. ${ }^{4}$ The countries in our dataset are shown in Appendix Table 7.

\section{Results}

To look at the general patterns of happiness and inequality-as well as to pick out the exceptions, which are often of great interest-we need to look at countries in our sample as a whole. Figure 2 shows the relationship between each country's inequality level and average happiness score. In Fig. 2 we grouped our sample of countries based on their geographical proximity and spatial distribution. The shape of the markers indicates country groups. The reason for this grouping is that countries within the same region may have

\footnotetext{
4 Although Hungary was observed twice in WVS, question used to measure income is only asked once in Hungary. Therefore, we had to drop Hungary from our sample to be able to run country fixed effects.
} 
similarities in terms of culture and other common features in the way the economic system has developed historically. We can see clear groups, especially for some country groups. For example, Western European countries clustered at the upper left corner, and SouthEast countries were clustered around between the lower left and middle of the figure. That is, West European countries which have low inequality and higher happiness. Nevertheless, at the same time, we observe Latin American countries which have high inequality and high average happiness.

We see more or less a similar relationship between inequality and life satisfaction in Appendix Figure 3. In Appendix Table 8, we show exact average happiness scores for each country.

We keep observations for which happiness, life satisfaction, all control variables, and the Gini coefficients are non-missing. Under these criteria, we have 188,398 observations. Table 1 shows descriptive statistics for our sample. We divided countries based on their Gini coefficient in 3 categories (high, middle, and low inequality countries as shown in Appendix Table 8) and mean values and standard deviations for these inequality groups are shown in Column 2,3 and 4, respectively. We found that most people were quite happy and satisfied with their lives. The average happiness score was 3.06 out of 4 , and the average life satisfaction score was 6.62 out of 10 .

The $t$-test results to check the existence of systematic differences between individuals living in low inequality and middle inequality countries, has been shown in the second column with significance stars. Similarly, the $t$-test results on the difference between individuals in the highest and middle inequality countries are shown in the fourth column with significance stars.

Table 1 indicates a positive linear relationship between inequality and happiness as the average happiness of respondents in low inequality countries (2.88) is statistically significantly lower than that in mid-inequality countries (3.07), which is lower than that in high inequality countries (3.19). We see a similar relationship between life-satisfaction and inequality. Also, as inequality level increases, people's support for income differences as incentives for individual effort slightly increases. Nevertheless, even in high inequality countries, the average attitude towards equality is 5.74 out of 10 . That shows that even in high-inequality countries, many people care about inequality. People living in low, middle and high inequality countries significantly differ from each other in terms of age and gender. Almost for every category of marital status, employment status, educational attainment and income scale, there are statistically significant differences between individuals in the lowest inequality countries and middle inequality countries as well as high inequality countries. Regarding GDP per capita, freedom score, freedom perception, perceived social mobility and fairness, we also observe significant differences in some t-test results. However, the differences for many of the variables in terms of magnitude across inequality groups are rather modest. Nevertheless, those differences have to be accounted for in a regression analysis.

Table 2 reports OLS estimates in which an extensive set of variables are controlled. In Model 1, we conduct a multilevel regression with a random intercept and a random slope of Gini coefficient. According to model 1, inequality is slightly, albeit insignificantly, negatively related to life satisfaction. However, the variance components $(\mathrm{SD}=1.120$. $\mathrm{SE}=0.121$ for life satisfaction and $\mathrm{SD}=0.049$. $\mathrm{SD}=0.220$ for life satisfaction) for the slope of Gini coefficient indicate significant country differences $(\chi 2(51)=3197.39$. $p<0.001$ for life satisfaction and $\chi 2(51)=3211.32$. $p<0.001$ for happiness). Therefore, this significant between country variation has to be accounted for. In Model 2, where country fixed effects are taken into account, we observe a negative and statistically significant 
Table 1 Descriptive statistics

\begin{tabular}{|c|c|c|c|c|}
\hline & Entire sample & Low inequality & Middle inequality & High inequality \\
\hline Gini & $40.21[10.38]$ & $29.59[3.39]^{* * *}$ & $36.58[3.79]$ & $50.12[7.37] * * *$ \\
\hline Happiness score (1-4) & $3.06[0.76]$ & $2.88[0.76]^{* * *}$ & $3.07[0.71]$ & $3.19[0.76]^{* * *}$ \\
\hline Life satisfaction (1-10) & $6.62[2.44]$ & $6.07[2.55]^{* * *}$ & $6.54[2.32]$ & $7.04[2.35]^{* * *}$ \\
\hline Attitude to equality (1-10) & $5.69[2.98]$ & $5.62[2.90]^{* * *}$ & $5.69[2.91]$ & $5.74[3.08]^{* *}$ \\
\hline Female & $0.52[0.50]$ & $0.53[0.50]^{* * *}$ & $0.52[0.50]$ & $0.50[0.50]^{* * *}$ \\
\hline Age & $40.98[16.05]$ & $42.67[16.46]^{* * *}$ & $43.42[16.38]$ & $38.14[15.05]^{* * *}$ \\
\hline \multicolumn{5}{|l|}{ Marital status } \\
\hline Married/ with partner & $0.64[0.48]$ & $0.67[0.47]^{* * *}$ & $0.68[0.47]$ & $0.60[0.49]^{* * *}$ \\
\hline Divorced/separated/widowed & $0.11[0.32]$ & $0.13[0.34]^{* * *}$ & $0.12[0.32]$ & $0.09[0.29]^{* * *}$ \\
\hline Single & $0.24[0.43]$ & $0.20[0.40]$ & $0.20[0.40]$ & $0.30[0.46]^{* * *}$ \\
\hline \multicolumn{5}{|l|}{ Employment status } \\
\hline Full time & $0.34[0.47]$ & $0.35[0.48]^{* *}$ & $0.35[0.48]$ & $0.33[0.47]^{* * *}$ \\
\hline Part time & $0.08[0.27]$ & $0.08[0.27]$ & $0.08[0.27]$ & $0.08[0.28]^{* *}$ \\
\hline Self-employed & $0.12[0.32]$ & $0.07[0.25]^{* * *}$ & $0.11[0.31]$ & $0.16[0.37]^{* *}$ \\
\hline Retired & $0.12[0.33]$ & $0.16[0.37]^{* * *}$ & $0.15[0.36]$ & $0.07[0.26]^{* * *}$ \\
\hline House-maker & $0.15[0.36]$ & $0.18[0.38]^{* * *}$ & $0.15[0.36]$ & $0.14[0.34]^{* * *}$ \\
\hline Student & $0.07[0.25]$ & $0.06[0.24]^{* * *}$ & $0.05[0.22]$ & $0.09[0.28]^{* * *}$ \\
\hline Unemployed & $0.09[0.29]$ & $0.08[0.27]$ & $0.08[0.27]$ & $0.11[0.32]^{* * *}$ \\
\hline Other emp. Status & $0.02[0.15]$ & $0.02[0.13]^{* * *}$ & $0.04[0.19]$ & $0.01[0.12]^{* * *}$ \\
\hline \multicolumn{5}{|l|}{ Educational attainment } \\
\hline Less than elementary school & $0.12[0.33]$ & $0.13[0.34]^{* * *}$ & $0.07[0.26]$ & $0.15[0.36]^{* * *}$ \\
\hline Completed elementary sch & $0.14[0.35]$ & $0.13[0.33]^{* * *}$ & $0.16[0.37]$ & $0.14[0.34]^{* * *}$ \\
\hline Incomp. Secondary sch & $0.15[0.36]$ & $0.11[0.32]^{* * *}$ & $0.16[0.37]$ & $0.18[0.38]^{* * *}$ \\
\hline Complete secondary sch & $0.35[0.48]$ & $0.38[0.49]^{* * *}$ & $0.35[0.48]$ & $0.34[0.47]^{* * *}$ \\
\hline Incomp. University & $0.07[0.26]$ & $0.07[0.25]^{* * *}$ & $0.08[0.27]$ & $0.07[0.26]^{*}$ \\
\hline Completed university & $0.16[0.36]$ & $0.18[0.39]^{*}$ & $0.18[0.38]$ & $0.13[0.33]^{* * *}$ \\
\hline Income scale & $4.63[2.32]$ & $4.59[2.23]^{* * *}$ & $4.71[2.36]$ & $4.60[2.35]^{* * *}$ \\
\hline GDP per capita (in 1000 USD) & $13.53[16.75]$ & $15.96[21.62]^{* * *}$ & $18.27[16.36]$ & $8.57[10.81]^{* * *}$ \\
\hline Freedom score (0-2 scale) & $1.24[0.79]$ & $1.00[0.88]^{* * *}$ & $1.35[0.70]$ & $1.34[0.75]$ \\
\hline Perceived freedom (1-10 scale) & $6.90[2.40]$ & $6.49[2.47]^{* * *}$ & $6.69[2.41]$ & $7.32[2.28]^{* * *}$ \\
\hline Perceived social mobility & $6.77[2.81]$ & $6.74[2.73]^{* * *}$ & $6.57[2.75]$ & $6.94[2.90]^{* * *}$ \\
\hline Perceived fairness & $0.52[0.50]$ & $0.53[0.50]^{* * *}$ & $0.51[0.50]$ & $0.51[0.50]$ \\
\hline $\mathrm{N}$ & 188,398 & 54,343 & 54,877 & 79,178 \\
\hline
\end{tabular}

The sample means and standard deviations for the full sample is in Column 1. The remaining columns provide sample means and standard deviations by the inequality level. $* p<0.05$, ** $p<0.01, * * * p<0.001$

relationship between inequality and life satisfaction as well as happiness at a $95 \%$ confidence level. In Model 3, 4, and 5, after accounting for country fixed effects, GDP per capita, total unemployment rate, and the unemployment rate for both genders, inequality is still negatively related to both happiness and life satisfaction at a 5\% significance level.

We reported OLS for ease of interpretation, as Ferrer-i-Carbonell and Frijters (2004) reports close estimates between ordered probit and OLS models. Ordered probit model estimates are also provided in Appendix Table 10 which are in line with OLS results. 


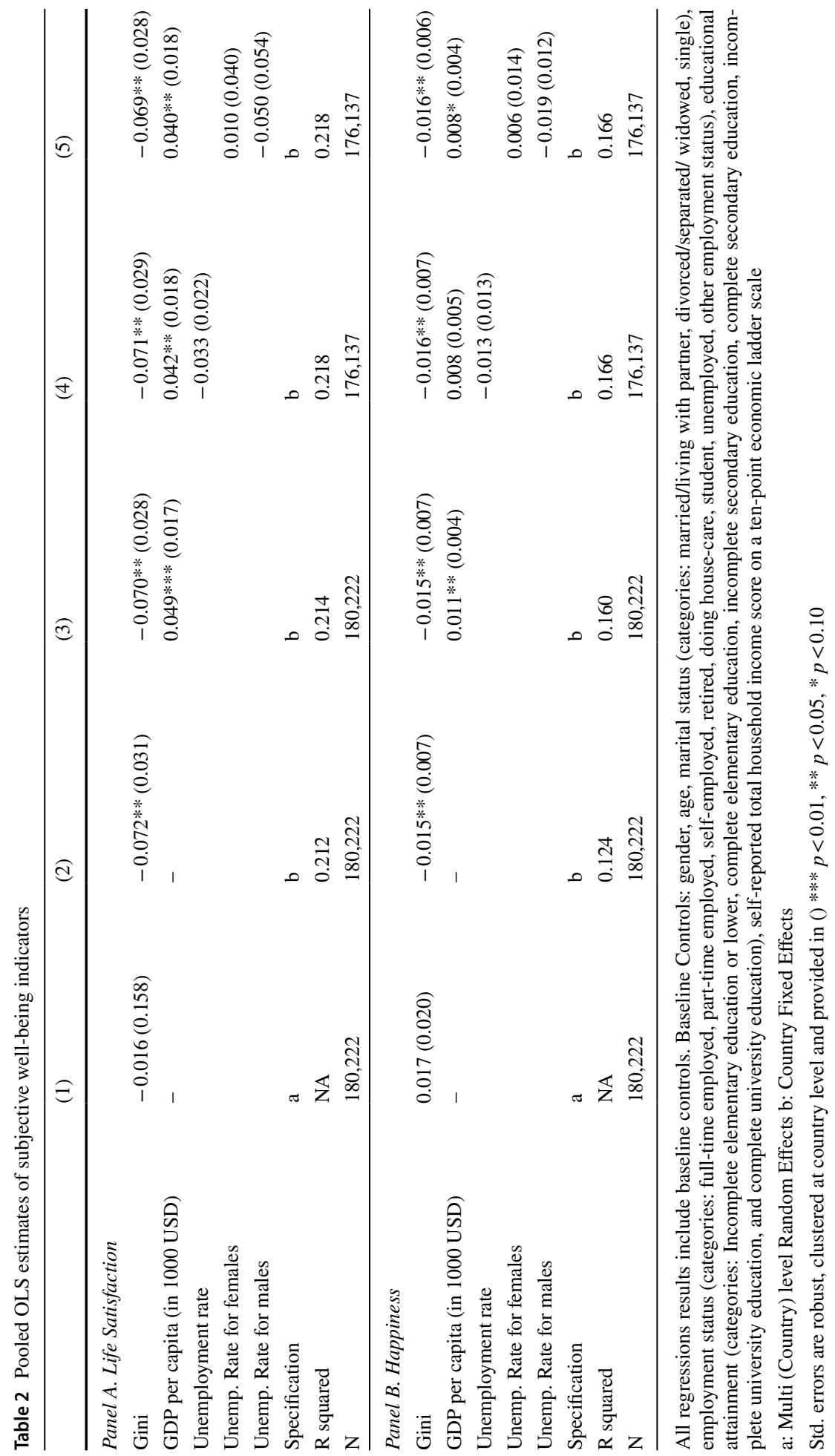


To see whether the inequality's effect is different for different income groups, we divide the respondents based on their self-reported household income on an economic ladder scale. Those who place themselves below the 6th step are categorized as the lower-income group, whereas those who place themselves on the 6th step or more are categorized as the upper-income group. Table 3 shows the OLS results. According to Model 1 and Model 3, inequality is negatively associated with life satisfaction and happiness at a $95 \%$ confidence interval for lower-income groups. This association is in line with our expectation that people who are relatively less well-off will be hurt by inequality. Interestingly, according to Model 2 and 5, we observe a negative relationship between inequality and subjective wellbeing, even for the upper-income group. As shown in model 3 and 6 of Table 3, the coefficient of the interaction term is insignificant for both life satisfaction and happiness that gives support to notion that the negative effect of inequality remains regardless of income level. The results stay the same even if we divide income groups in 3 categories (online Appendix Table 1).

Appendix Table 11 provides the same models estimated for different country groups. According to these results, the negative association between inequality and life satisfaction is mainly driven by European and other countries (mostly English speaking countries). For African and Latin American countries, there is even a positive relationship between inequality and life satisfaction. That suggests that the effect of inequality is not uniform and may change depending on the cultural context.

We also examine people's attitudes towards inequality. Table 4 shows both the average and the distribution of attitudes towards income inequality for different income groups. According to Table 4, higher-income individuals are more likely to support income differences as incentives for individual effort as their average out of 10 is 6.09 , whereas the average degree of supporting income differences is 5.49 for lower-income groups. Also, the difference between the two groups is statistically significant at the $1 \%$ significance level. The lower-income individuals are more of the opinion that income inequality should be corrected as about $16 \%$ of lower-income individuals give full support to the statement that incomes should be made more equal, whereas only about $10 \%$ of higher-income individuals give full support to the same statement. Also, $40 \%$ of the upper-income group replied as 5 or lower to income equality questions, which shows that a considerable amount of upper-income group supports the correction of income inequality to some extent. Even if we divide income into 3 categories, approximately $15 \%$ the lower income groups support necessity of increasing income differences (online Appendix Table 2).

On the other hand, we see embracement of some inequality, too. $53 \%$ of the entire sample, $49 \%$ of the lower-income group, and $60 \%$ of the higher income group answered 6 or higher to income equality questions. One can read these as higher-income individuals are justifying their position, but also almost half of lower-income individuals consider inequality as necessary for individual effort. Even more tellingly, both $14 \%$ of lower-income groups and higher-income groups give full support to the statement that income differences are necessary as incentives for individual effort. Moreover, we provide in the Appendix Table 8 that countries overall approach to inequality are widely different from each other. For example, Slovenia which is a low inequality country is least supportive of income inequality with an average of 4.10 . On the other hand, Ghana which is a high inequality country is the most supportive of income inequality with an average of 7.32 out of 10 . When the correlation between the gini coefficient and attitude toward inequality is checked (Appendix Table 9), we observe a positive but insignificant relationship. 


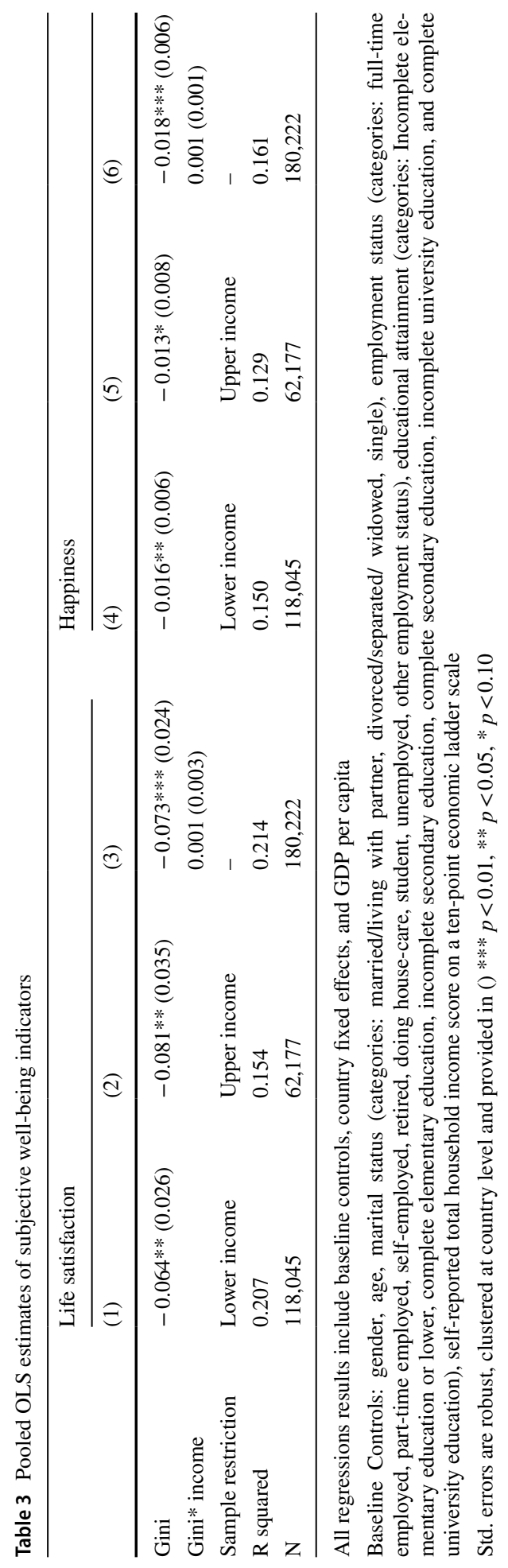


Table 4 Attitudes towards income inequality

\begin{tabular}{llll}
\hline & Entire sample & Lower income & Upper income \\
\hline Incomes should be made more equal (1) & $13.87 \%$ & $15.95 \%$ & $9.88 \%$ \\
$2-5$ & $33.36 \%$ & $35.14 \%$ & $29.96 \%$ \\
6-9 & $38.66 \%$ & $34.76 \%$ & $46.11 \%$ \\
We need larger income differences as incen- & $14.12 \%$ & $14.15 \%$ & $14.05 \%$ \\
$\quad$ tives for individual effort (10) & $5.69[2.98]$ & $5.49[3.05]$ & $6.09 * * *[2.82]$ \\
Mean attitude towards inequality & 188,398 & 123,662 & 64,736 \\
$\mathrm{~N}$ & & & \\
\hline
\end{tabular}

Mean coefficients; sd in brackets. $* p<0.05, * * p<0.01, * * * p<0.001$

\subsection{Underlying Mechanism}

Previous studies pointed out three variables (perceived freedom, social mobility and fairness perception) that could be a relevant factor in this relationship. Table 2 shows that the Gini coefficient is negatively associated with life satisfaction $(\beta=-0.070, p<0.05)$ and happiness $(\beta=-0.015, p<0.05)$. There is a negative relationship between the Gini coefficient and freedom perception $(\beta=-0.044)$ at $90 \%$ confidence level (Appendix Figure 5). We did not detect a statistically significant relationship between the Gini coefficient, social mobility perception and perceived fairness. Appendix Figure 5 also shows statistically significant effects of all three variables on wellbeing measures. When freedom perception is controlled, the relationship between the Gini coefficient becomes smaller (Model 1 in Table 5). Sobel test result $(\mathrm{Z}=-16.91, p=0.00)$ and the bootstrapped confidence interval (BCI) $(-0.0150,-0.0116)$ obtained with 1,000 replications and bias correction following Preacher and Hayes (2004)'s methodology show significant indirect effects. Still, the effect of the Gini coefficient on life satisfaction is statistically significant and negative (Model 1 in Table 5). Similarly, freedom perception partially mediates the Gini coefficient and happiness relationship (Sobel $Z=-16.58, p=0.06$; (BCI: $-0.0027,-0.0020$ )). Around 15\% of total effect is mediated through freedom perception. When country-level freedom scores obtained from Freedom House are accounted, we still observe a negative and statistically significant relationship between inequality and life satisfaction as well as happiness at $95 \%$ confidence level (Model 2 of Table 5).

Secondly, when perceived social mobility is taken into account, the effect of Gini coefficient on life satisfaction is still negative and statistically significant (Model 3 of Table 5). According to Sobel test $(\mathrm{Z}=-6.73, p=0.00)$ and bootstrapped CI results $(-0.0013,-0.0008)$, there is significant indirect effect through perceived social mobility. We see similar results for happiness (Sobel Test: $=-6.83, p=0.00$, BCI: $-0.0005,-0.0003)$. However, only a mere around $2 \%$ of the total effect is mediated through social mobility perception.

For studying the mediating role of fairness, in model 4 and 5, a two point and ten-point fairness perception scale are added. The relationship between the Gini coefficient and life satisfaction, as well as happiness, disappears when perceived fairness is included in the models. Sobel test $(Z=5.16, p=0.00)$ and bootstrapped CI results $(0.0018,0.0035)$ show that, fairness perception provides a significantly indirect effect channel for the relationship between the Gini coefficient and life satisfaction. In a similar fashion, fairness perception is also a significant mediator of the relationship between the Gini coefficient and happiness 


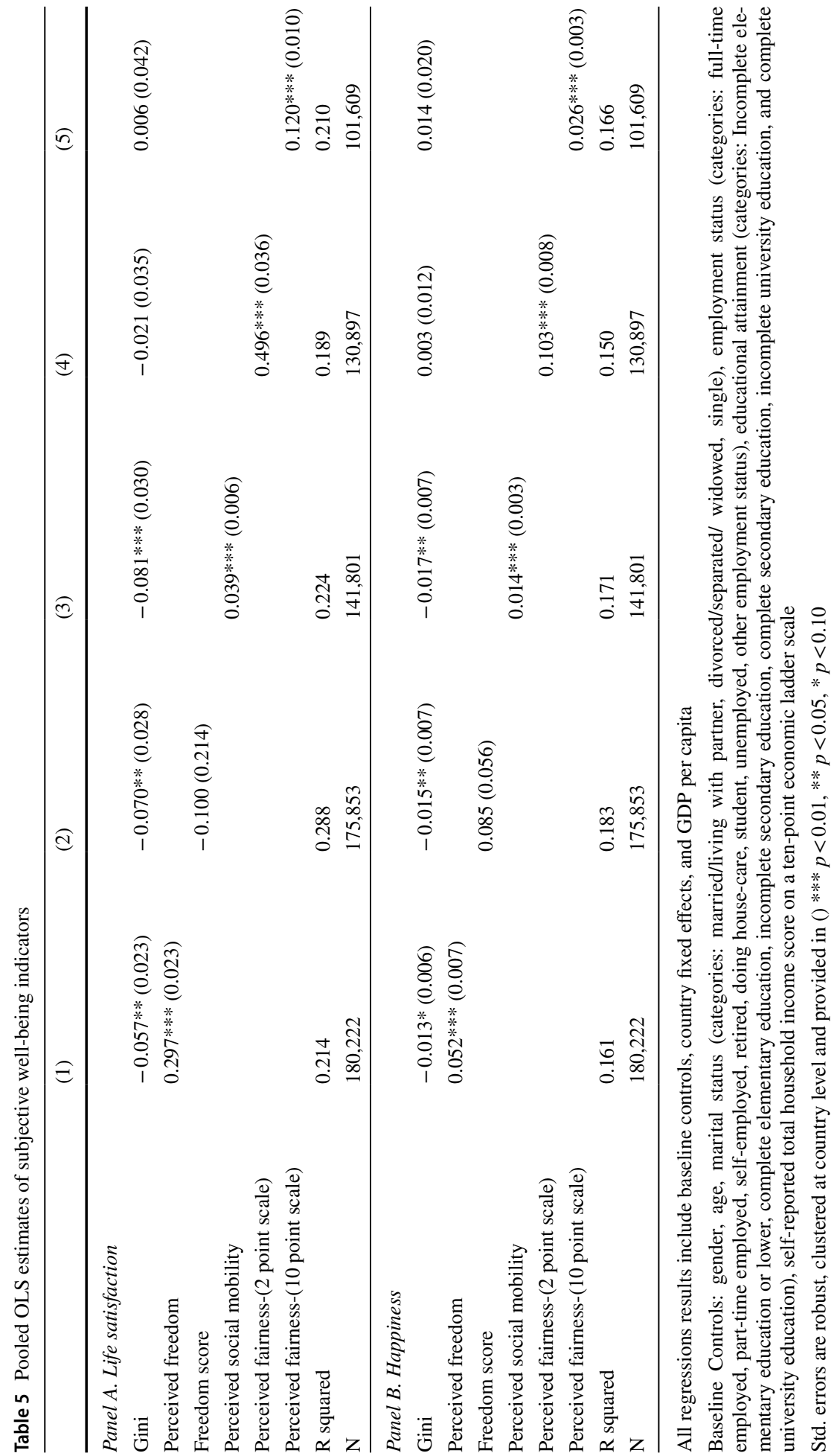


(Sobel Test: $=5.1, p=0.00$, BCI: 0.0004, 0.0007). Appendix Table 12 reports the ordered probit estimates for the same models which points to almost the same results as Table 5.

To check whether the insignificance of the Gini coefficient in Model 5 stems from possible high correlation between fairness and inequality, Table 9 presents that there is a mere -0.12 correlation between fairness scores and the Gini coefficient. Also, when checked for multicollinearity, VIF's of fairness 2-point scale and 10-point scale are 1.09 and 1.10, respectively. As this is a rather low score, we can safely ignore multicollinearity.

In Table 6, we report the results for lower and upper-income groups when freedom perceptions, the perceived social mobility and fairness perception are included in the models. There is still a statistically significant relationship between the Gini coefficient and subjective well-being indicators in models 1, 2, 5 and 6 similar to what is reported in Table 5. Again, for both lower and upper-income groups, there is no statistically significant relationship between the Gini coefficient and life satisfaction as well as happiness when fairness perception is included in the models.

We also conducted two robustness checks. First, we included Cyprus, the country that experienced drop in GDP per capita in the survey years. The results shown in Appendix Table 13 stayed almost the same. Moreover, adding country level education and unemployment does not change the main results of Table 5.

Furthermore, in Table 14, fairness perception is added to the specification that was run for each country group. For the European and mainly English speaking other countries that are driving the negative relationship between the Gini coefficient and SWB in Table 2, the direct effect of the Gini coefficient is eliminated. Interestingly, after taking into account fairness perception in Asian countries, the Gini coefficient has a significant negative relationship with life satisfaction. That is, fairness perception plays a mediating role in European countries but it plays a suppressing role in Asian countries. This finding suggests that in different cultural contexts people's ingrained values might bring different evaluations of fairness and also inequality which is elaborated in the next section.

\section{Discussion}

Based on more than 180,000 observations from 51 countries, we find a negative relationship between life satisfaction, happiness and the Gini coefficient. Interestingly, we find that income inequality also hurts higher-income groups. Our findings support the previous studies (e.g., Alesina et al. (2004); Morawetz et al. (1977); Oishi and Kesebir (2015)).

We observe large scale support for some inequality, too, as even almost half of the lower-income group people support some inequality. This is in line with the findings of Eriksson and Simpson (2012); Kiatpongsan and Norton (2014); Norton and Ariely (2011). Our study shows that preference for some inequality is not particular to the US but holds for many countries.

These two conflicting sets of findings, negative relationship between income inequality and subjective well-being, together with large scale endorsement of some inequality, can be reconciled by looking at what inequality signifies. The negative effect of inequality survives after taking into account freedom and social mobility perception. Social mobility perception is about one's future life and the cumulating evidence suggests that present states are weighted disproportionately more than the future (Frederick et al., 2002), mobility perceptions may not be sufficient to overcome the negative effect of inequality on the present well-being. 





We find that fairness perception is a significant channel for the relationship between inequality and wellbeing. These findings are in line with the findings of Shaw and Olson (2014); Starmans et al. (2017). In his account of the long historical progress of humanity, Deaton (2013) also differentiates between fair and unfair types of inequality. The first type, which is the result of innovations and their adaptation in society at different paces, is depicted as fair. The second type, which is the result of the rent-seeking behavior of a well-to-do group, is depicted as unfair. Moreover, Amartya Sen (1992) argues that there are various aspects of life for which equality of it is demanded, and that equality in one pursuit usually entails inequality in another aspect due to human diversity. Thus, certain types and levels of income inequality may not be genuinely disapproved if people see it fair or enough fairness in other domains.

Having said that, our results are within the confines of the experiences in the sample countries. That is, we cannot claim anything about what would happen if the Gini coefficient exceeded a certain threshold. In such a case, it might be difficult to attribute the difference between earnings only to differences in merit and could lead to a major upheaval in society as explained by Acemoglu and Robinson (2000).

On the other hand, Appendix Figure 4 shows that even high inequality countries like China and Rwanda can have very high fairness perception. There could be two reasons why it is possible for a country to be highly unequal and perceived as fair. Firstly, for actual inequality to hurt people, it needs to be perceived. However, many studies suggest that people incorrectly perceive income distribution because of limited information and/or cognition (Cruces et al., 2013; Gimpelson \& Treisman, 2018; Iacono \& Ranaldi, 2021). Moreover, rather than actual inequality, perceived inequality matters more for redistribution preferences (Choi, 2019; Gimpelson \& Treisman, 2018). In line with this argument, we find inequality to hurt wellbeing mostly in the developed countries in Europe and mainly English speaking countries (Appendix Table 11). People in these countries might be more aware of inequality as the information regarding inequality might be disseminated more transparently. Secondly, culture can play a role for imparting values that could even embrace inequality. There is a large-scale difference between Confucian ethics that considers in-group favoritism as a fair treatment as opposed to Western ethics which demands equal weight to everyone (Asma, 2013; Palais, 1984). The different approach to equality can explain why fairness perception play a suppressing role in Asian countries according to Appendix Table 14. However, Asian countries in our sample are not confined to only those in which Confucianism is prevalent. Further studies are necessary to delineate how different ethical values impact perceiving fairness in unequal settings.

Our results also reveal that income inequality is more detrimental in terms of life satisfaction than happiness. For example, Alesina et al. (2004)'s finding of a smaller effect of inequality on happiness for the USA and a larger effect of inequality on life satisfaction for the European countries can be reconciled by the different domains of well-being measured by life satisfaction and happiness. Life satisfaction is more related to the dimension of well-being that is related to aspirations, whereas happiness is more close to the daily emotional dimension of well-being (Kahneman \& Riis, 2005). This implies that inequality disturbs people's cognitive aspect of well-being more than its affective domain. This result can be partially because the life satisfaction score (10 point Likert scale) is more precisely measured than the happiness score (4 point Likert scale).

One of the weaknesses of the current study is about the Gini coefficient as one measure income inequality. The Gini coefficient has limitations such as giving less weight to changes in tails of the income distribution, and according to Atkinson et al. (2011), the largest changes in income distribution occurred in the upper tail of income distribution. 
Moreover, we tried several instruments (progressivity of taxes, public social expenditure categories) to study the causal effect of inequality on SWB, however none of our instruments passed the F-test. Future studies can shed light on the causal effect of inequality using COVID-19 pandemic as it exogenously deepened inequality in many countries worldwide.

\section{Conclusion}

This study tries to find an answer to the following question: How is inequality corrosive to subjective well-being? In our study of approximately 180,000 participants from 51 different countries, we find that even after taking into account countries' attributes that are time-invariant with country fixed effects specification, inequality is associated with lower life satisfaction and happiness scores for individuals. On the other hand, more than half of the respondents support some inequality for sustaining individual effort. This suggests that certain types and some degrees of inequality may be socially acceptable; therefore, it might not hurt people's life satisfaction nor their happiness.

To uncover the mechanism behind the effect of inequality on well-being, we examined the following sets of explanations: fairness, freedom, and social mobility. Overall, freedom and social mobility partially mediate the negative effect of inequality on subjective wellbeing whereas fairness perception fully explains that relationship. Our bottom line is that inequality disturbs people both lower-income and higher-income groups primarily due to fairness concerns.

The findings of this study suggest that if some inequality is considered as necessary to keep people industrious, then, to protect people from the damaging effects of inequality, our recommendation is to ensure fairness, transparency in social life should be enhanced.

\section{Appendix}

See Figs. 3, 4 and 5.

See Tables 7, 8, 9, 10, 11, 12, 13 and 14 . 


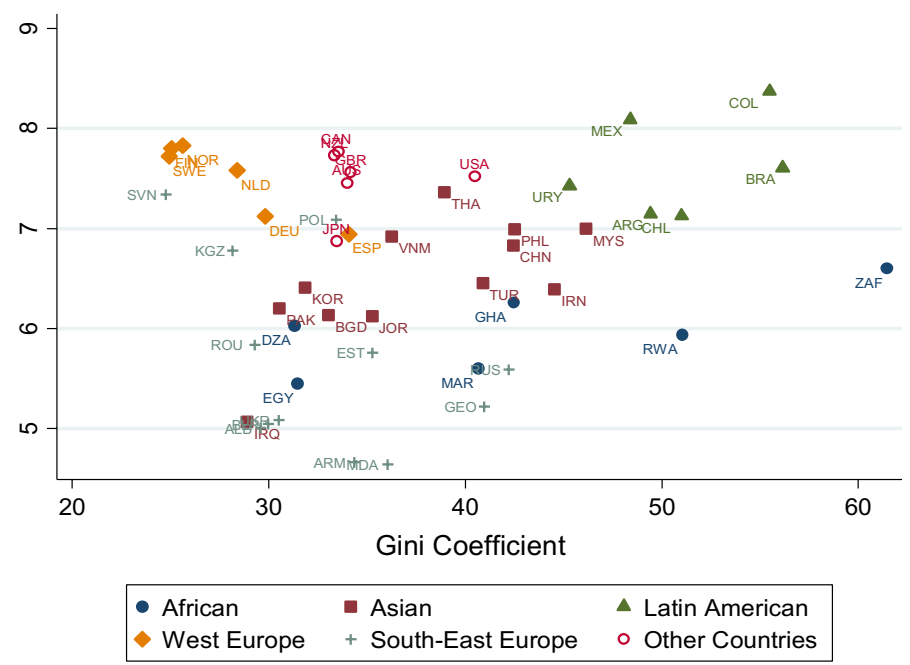

Fig. 3 Inequality and life satisfaction relationship

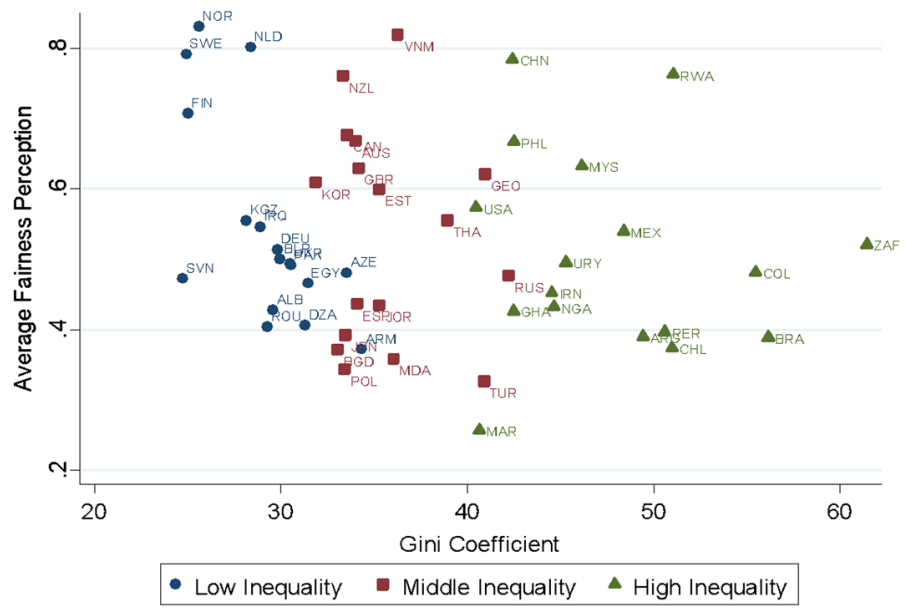

Fig. 4 Inequality and fairness relationship 

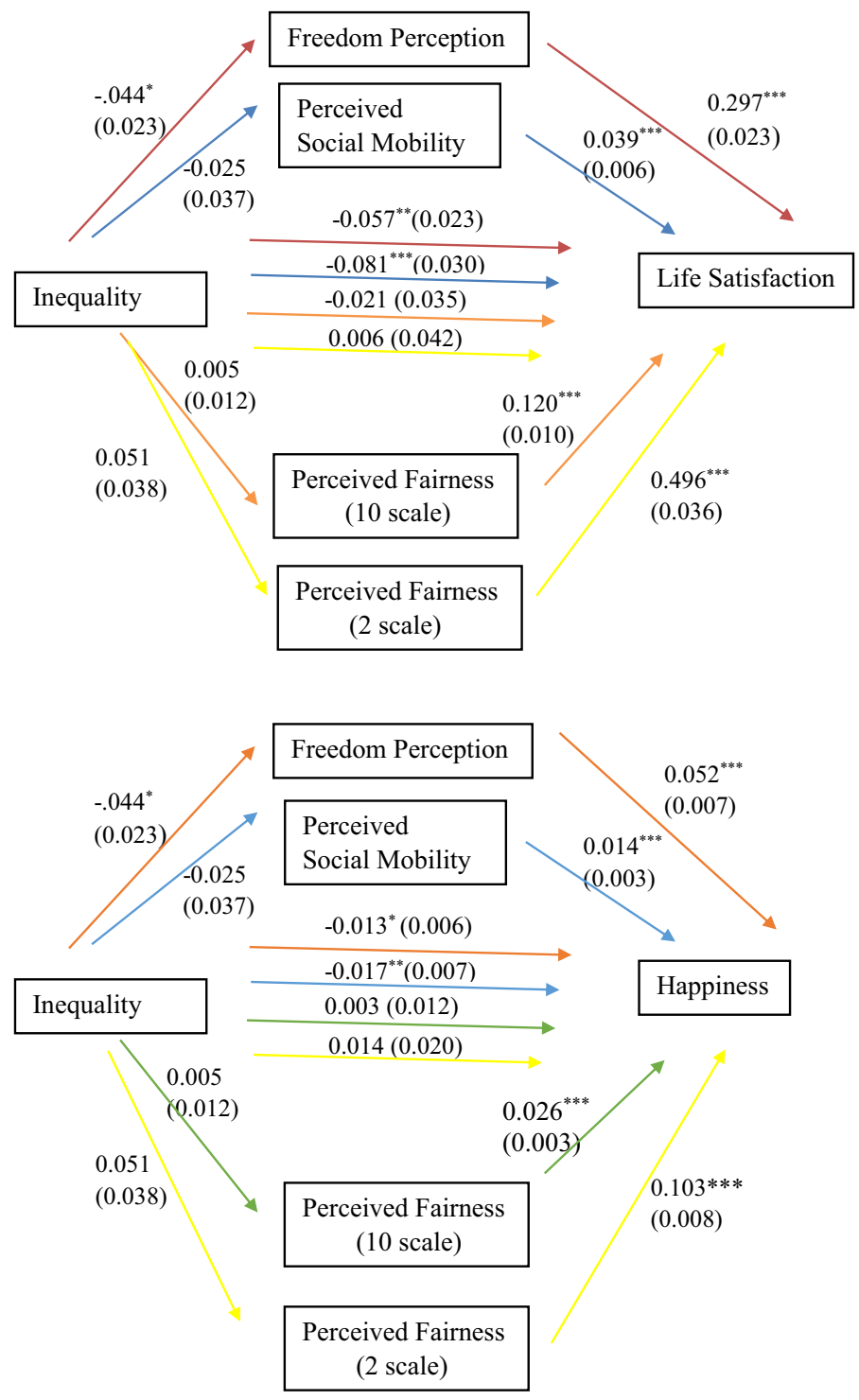

Fig. 5 Mediation analysis results 
Table 7 Gini coefficients of the countries in the sample

\begin{tabular}{|c|c|c|c|c|c|c|}
\hline Country & Wave 1 & Wave 2 & Wave 3 & Wave 4 & Wave 5 & Wave 6 \\
\hline Albania & - & - & 27 & 31.7 & - & - \\
\hline Algeria & - & - & - & 35.3 & - & 27.6 \\
\hline Argentina & 42.8 & 46.8 & 48.9 & 49.8 & 48.3 & 42.3 \\
\hline Armenia & - & - & 36.2 & - & - & 31.3 \\
\hline Australia & 31.3 & - & 32.6 & - & 35.4 & 34.7 \\
\hline Azerbaijan & - & - & 34.7 & - & - & 31.8 \\
\hline Bangladesh & - & - & 32.9 & 33.2 & - & - \\
\hline Belarus & - & $M$ & 32.3 & - & - & 27.1 \\
\hline Brazil & - & 60.5 & - & - & 55.9 & 51.5 \\
\hline Canada & - & - & - & 33.3 & 33.8 & - \\
\hline Chile & - & 57.3 & 54.9 & 52.8 & 48.2 & 47.6 \\
\hline China & - & $M$ & $M$ & $M$ & 42.8 & 42.2 \\
\hline Colombia & - & - & 56.9 & 58.7 & 55 & 53.5 \\
\hline Egypt & - & - & - & 32.8 & 31.1 & 29.8 \\
\hline Estonia & - & - & 39.5 & - & - & 32.5 \\
\hline Finland & $M$ & - & 22.4 & - & 27.6 & - \\
\hline Georgia & & & 37.1 & - & 41.7 & 40.1 \\
\hline Germany & - & - & 25.9 & - & 31.8 & 31.4 \\
\hline Ghana & - & - & - & - & 42.8 & 42.2 \\
\hline Iran & - & - & - & 44.1 & 44.8 & - \\
\hline Iraq & - & - & - & $M$ & 28.6 & 29.5 \\
\hline Japan & 30.4 & $M$ & 32.3 & 33.7 & 32.9 & 33.6 \\
\hline Jordan & - & - & - & 37 & 33.9 & 33.7 \\
\hline Kyrgyzstan & - & - & - & 28.7 & - & 27.8 \\
\hline Malaysia & - & - & - & - & 46 & 46.3 \\
\hline Mexico & $M$ & 51 & 48.5 & 51.7 & 46 & 48.1 \\
\hline Moldova & - & - & 36.9 & 35.8 & 35.4 & - \\
\hline Morocco & - & - & - & 40.6 & 40.7 & M \\
\hline Netherlands & - & - & - & - & 30 & 27.6 \\
\hline New Zealand & - & - & 33.9 & 33.5 & - & 32.3 \\
\hline Nigeria & - & 45 & 51.9 & 40.1 & - & 43 \\
\hline Norway & - & - & 24.3 & - & 27.1 & - \\
\hline Pakistan & - & - & 28.7 & 30.4 & - & 30.7 \\
\hline Peru & - & - & 53.7 & 51.8 & 51.7 & 45.1 \\
\hline Philippines & - & - & 46 & 42.8 & - & 42.2 \\
\hline Poland & - & 26.7 & 32.3 & - & 34.5 & 32.4 \\
\hline Romania & - & - & 31.1 & - & 29.8 & 27.3 \\
\hline Russian Federation & - & 48.4 & 46.1 & - & 41 & 39.8 \\
\hline Rwanda & - & - & - & - & 52 & 50.4 \\
\hline Slovakia & - & 19.5 & 25.8 & - & - & - \\
\hline Slovenia & - & - & 29.2 & - & 24.6 & 24.9 \\
\hline South Africa & $M$ & 59.3 & 60.7 & 57.8 & 64.8 & 63.4 \\
\hline South Korea & $M$ & $M$ & $M$ & $M$ & 31.7 & 32 \\
\hline Spain & $M$ & $M$ & $M$ & 33.3 & 33.1 & 35.7 \\
\hline
\end{tabular}


Table 7 (continued)

\begin{tabular}{lllllll}
\hline Country & Wave 1 & Wave 2 & Wave 3 & Wave 4 & Wave 5 & Wave 6 \\
\hline Sweden & - & - & - & 24.3 & 26.4 & 26.9 \\
Thailand & - & - & - & - & 39.8 & 37.8 \\
Turkey & - & 43.5 & 41.3 & 41.4 & 38.4 & 40 \\
Ukraine & - & - & 35.2 & - & 29.8 & 24.5 \\
United Kingdom & - & - & 34 & - & 34.3 & - \\
United States & - & - & 40.2 & 40.4 & 41.1 & 40.4 \\
Uruguay & - & - & $\boldsymbol{M}$ & - & 47.2 & 43.4 \\
Vietnam & - & - & - & 37 & 35.8 & - \\
\hline
\end{tabular}

'-' denotes that a survey was not conducted in that year whereas 'M' denotes that Gini coefficient is missing for that conducted survey 


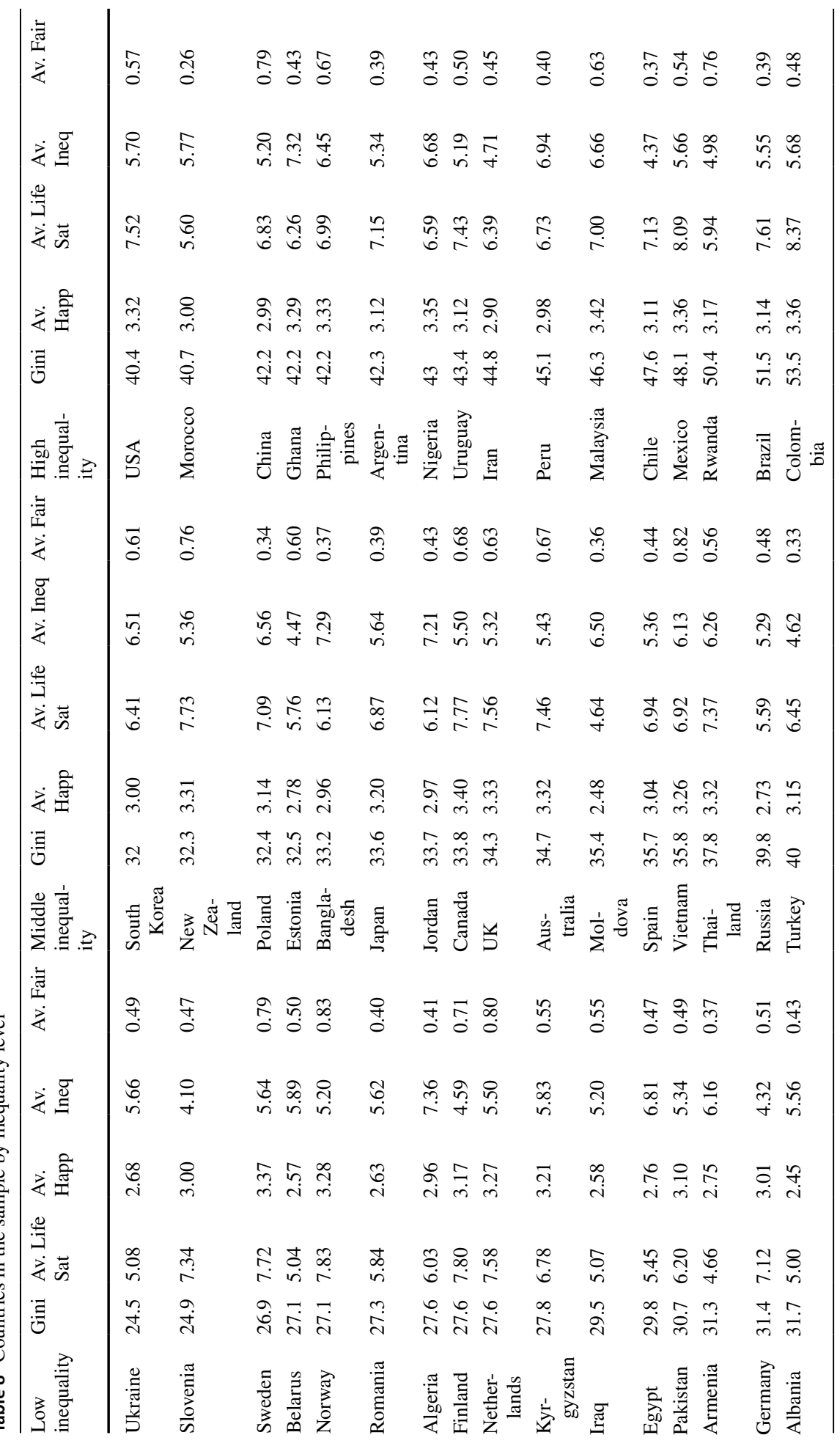




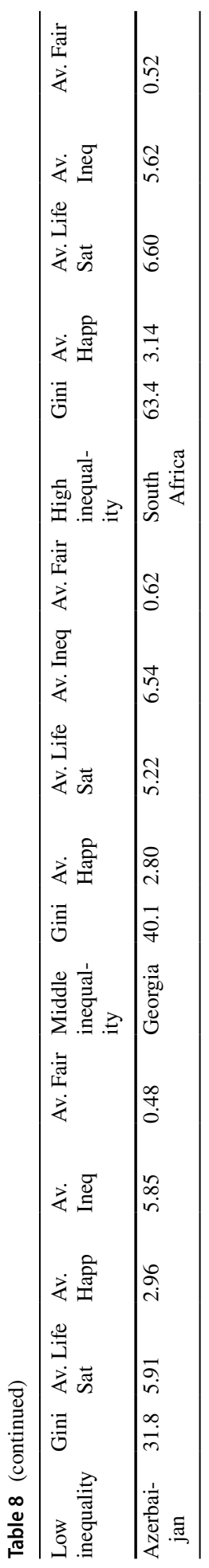




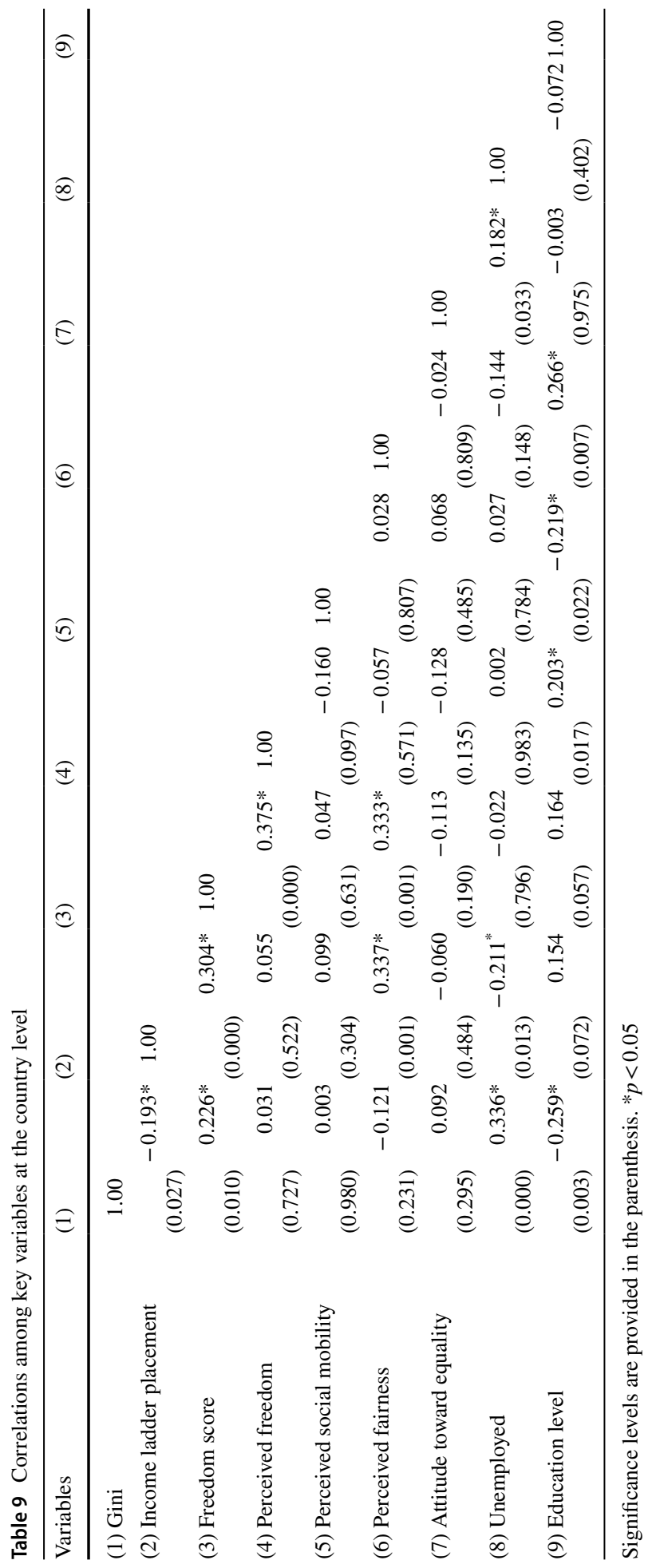


Table 10 Ordered probit estimates of subjective well-being indicators
(1)
(2)
(3)
(4)

\begin{tabular}{|c|c|c|c|c|}
\hline \multicolumn{5}{|l|}{ Panel A. Life Satisfaction } \\
\hline Gini & $-0.031 * *(0.014)$ & $-0.030^{* *}(0.013)$ & $-0.030 *(0.013)$ & $-0.030^{* *}(0.013)$ \\
\hline $\begin{array}{l}\text { GDP per capita (in } 1000 \\
\text { USD) }\end{array}$ & - & $0.020 * * *(0.008)$ & $0.017 * *(0.008)$ & $0.016 *(0.008)$ \\
\hline Unemployment rate & & & $-0.017 *(0.010)$ & \\
\hline Unemp. Rate for females & & & & $0.004(0.019)$ \\
\hline Unemp. Rate for males & & & & $-0.024(0.025)$ \\
\hline Specification & $\mathrm{b}$ & $\mathrm{b}$ & $\mathrm{b}$ & $\mathrm{b}$ \\
\hline Pseudo R squared & 0.051 & 0.052 & 0.053 & 0.053 \\
\hline $\mathrm{N}$ & 180,222 & 180,222 & 176,137 & 176,137 \\
\hline \multicolumn{5}{|l|}{ Panel B. Happiness } \\
\hline Gini & $-0.024 * *(0.011)$ & $-0.024 * *(0.011)$ & $-0.026 * *(0.010)$ & $-0.025^{* *}(0.010)$ \\
\hline $\begin{array}{l}\text { GDP per capita (in } 1000 \\
\text { USD) }\end{array}$ & - & $0.018 * *(0.007)$ & $0.013(0.008)$ & $0.012 *(0.007)$ \\
\hline Unemployment rate & & & $-0.020(0.019)$ & \\
\hline Unemp. Rate for females & & & & $0.010(0.021)$ \\
\hline Unemp. Rate for males & & & & $-0.032 *(0.019)$ \\
\hline Specification & $\mathrm{b}$ & $\mathrm{b}$ & $\mathrm{b}$ & $\mathrm{b}$ \\
\hline Pseudo R squared & 0.077 & 0.078 & 0.081 & 0.081 \\
\hline $\mathrm{N}$ & 180,222 & 180,222 & 176,137 & 176,137 \\
\hline
\end{tabular}

All regressions results include baseline controls. Baseline Controls: gender, age, marital status (categories: married/living with partner, divorced/separated/ widowed, single), employment status (categories: fulltime employed, part-time employed, self-employed, retired, doing house-care, student, unemployed, other employment status), educational attainment (categories: Incomplete elementary education or lower, complete elementary education, incomplete secondary education, complete secondary education, incomplete university education, and complete university education), self-reported total household income score on a ten-point economic ladder scale

b: Country Fixed Effects

Std. errors are robust, clustered at country level and provided in () $* * * * 00.01, * * p<0.05, * p<0.10$ 


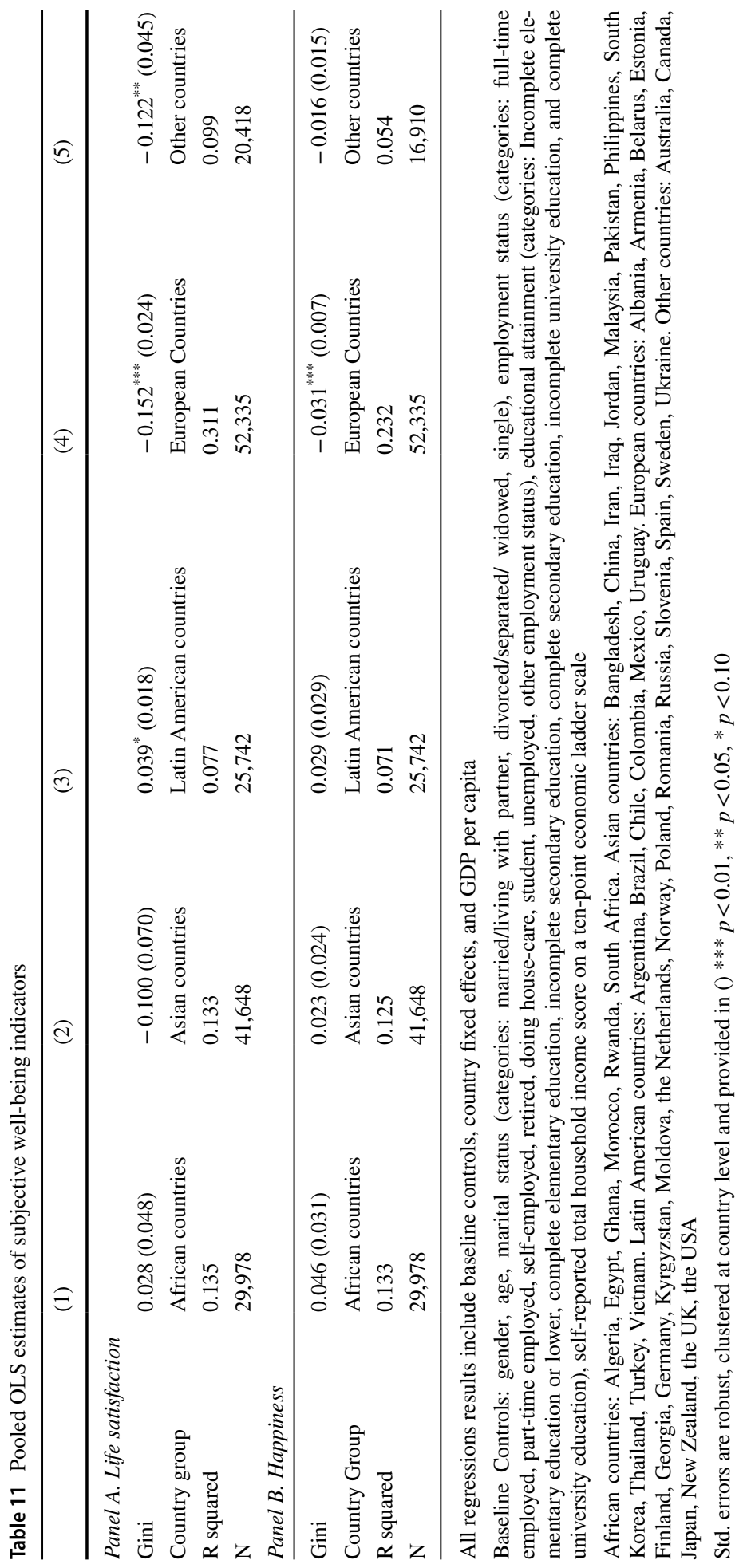




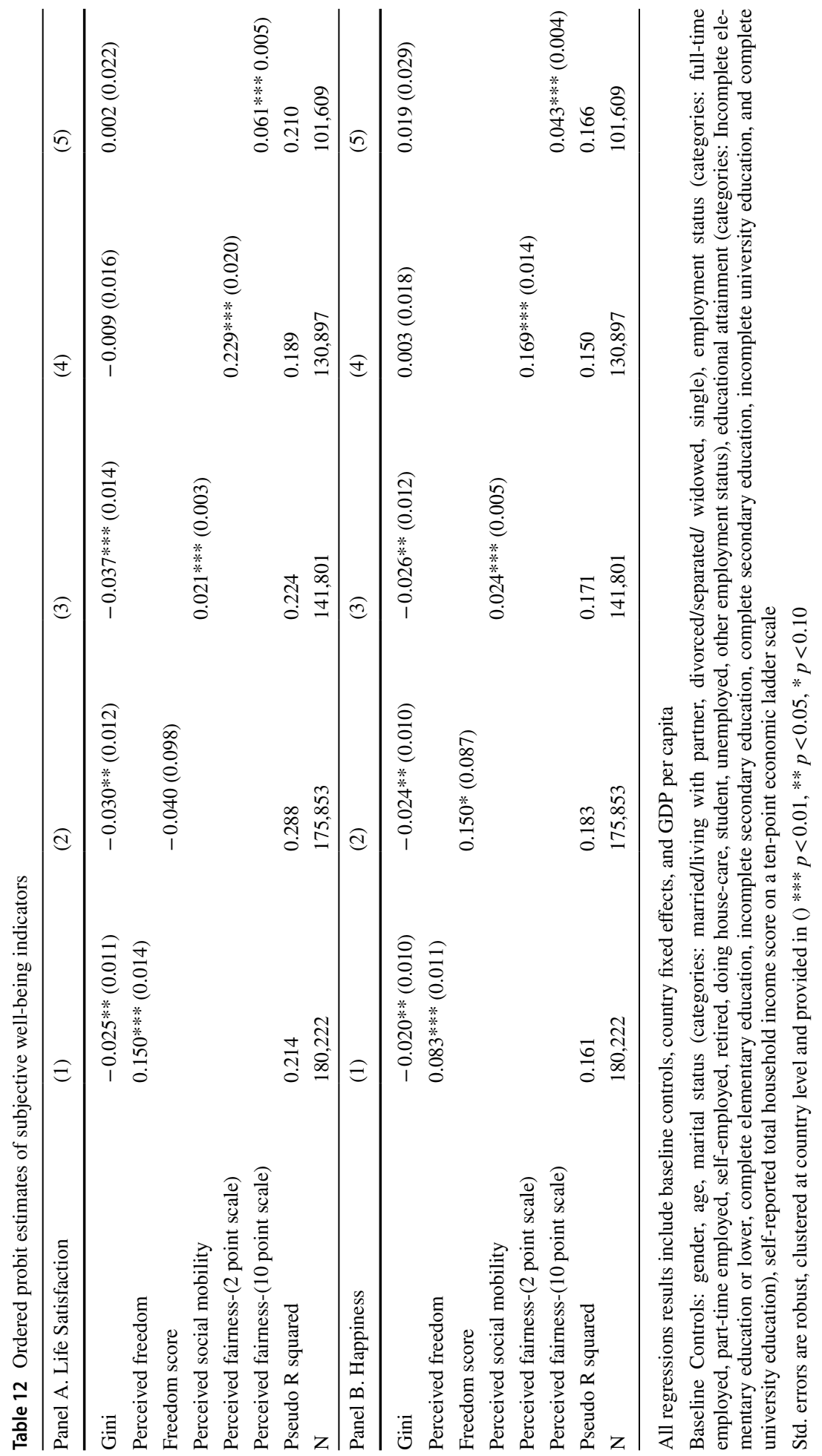




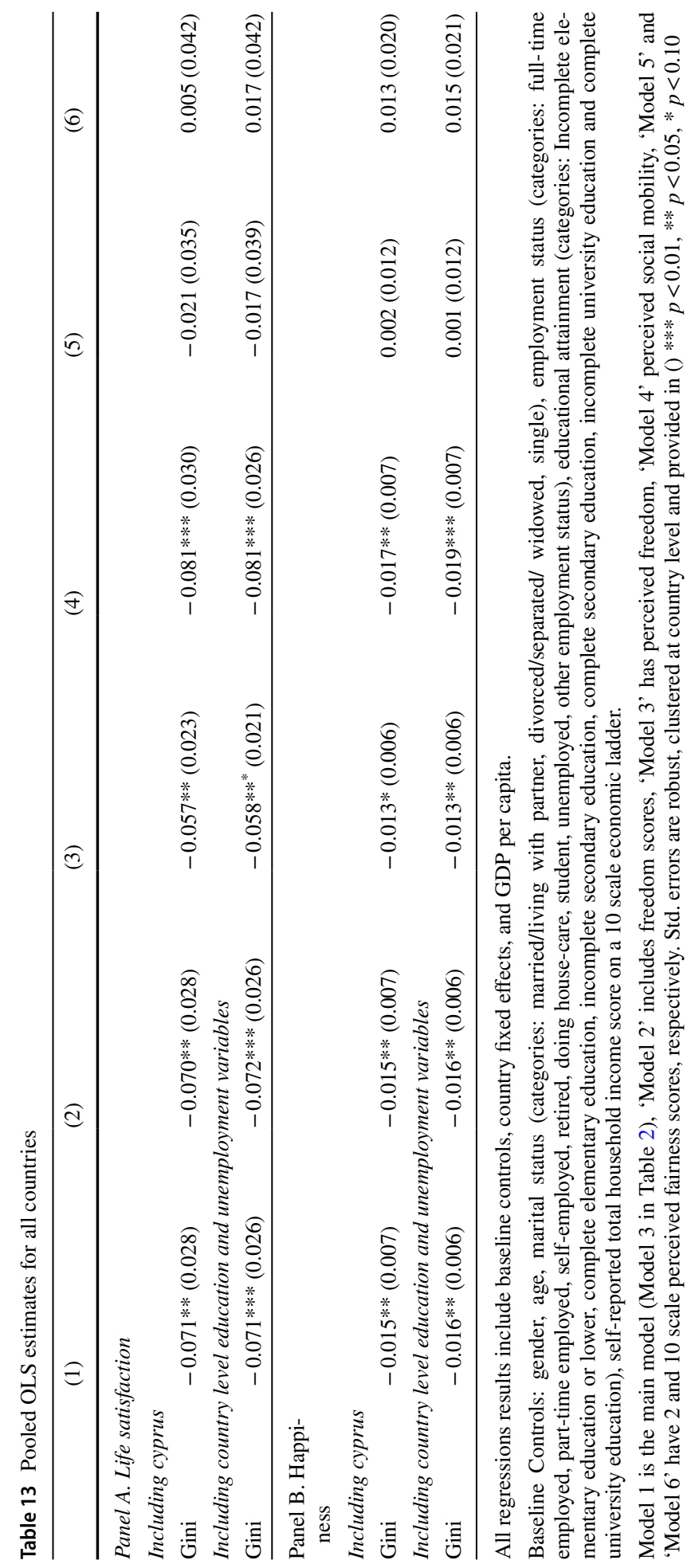




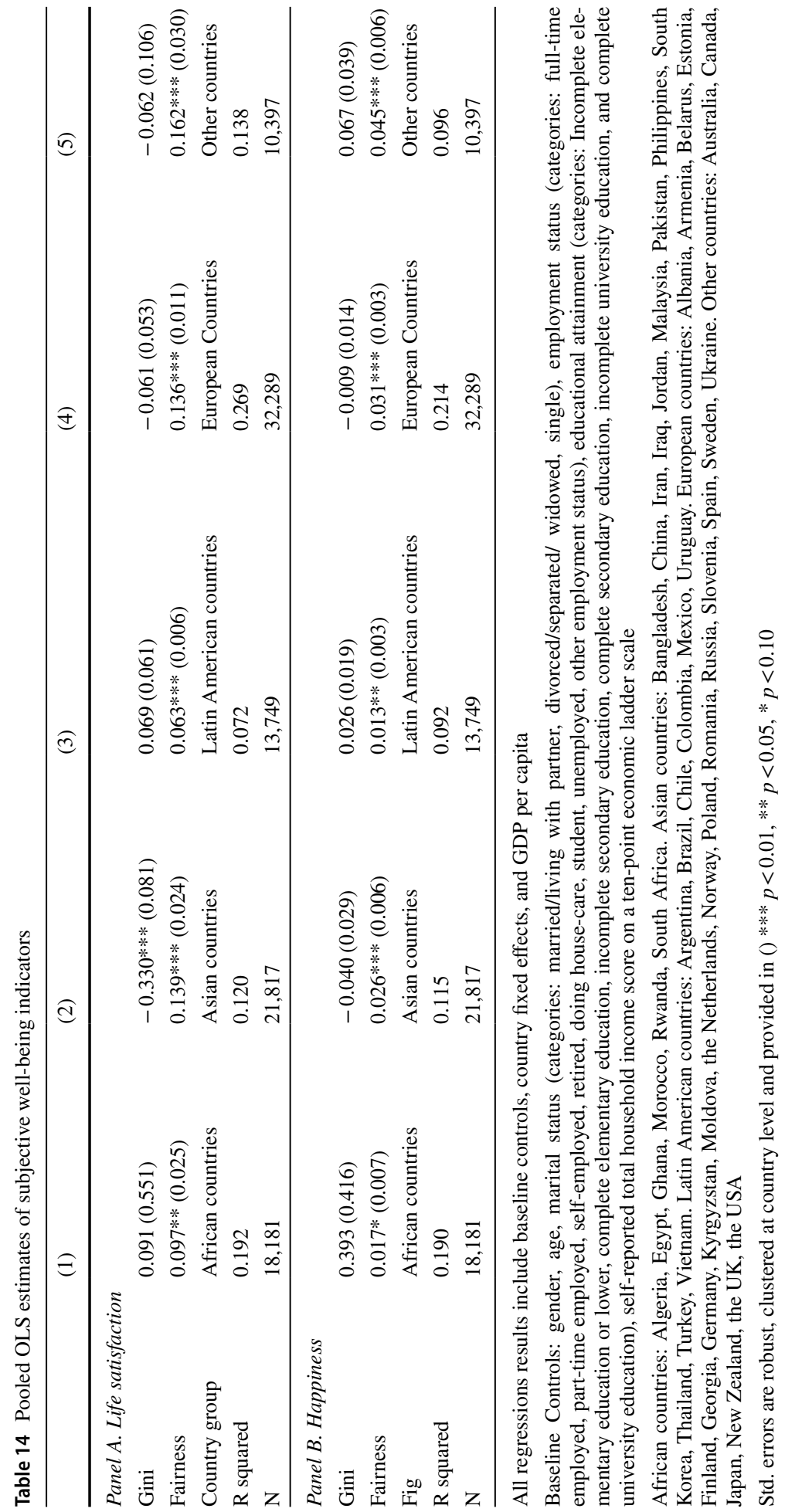


Supplementary Information The online version contains supplementary material available at https://doi. org/10.1007/s11205-021-02711-w.

\section{Declaration}

Conflict of interest The author declares that there is no conflict of interest regarding the publication of this article.

\section{References}

Acemoglu, D., \& Robinson, J. A. (2000). Why did the West extend the franchise? Democracy, inequality, and growth in historical perspective. The Quarterly Journal of Economics, 115(4), 1167-1199

Alesina, A., Di Tella, R., \& MacCulloch, R. (2004). Inequality and happiness: Are Europeans and Americans different? Journal of Public Economics, 88(9), 2009-2042. https://doi.org/10.1016/j.jpubeco. 2003.07.006

Asma, S. T. (2013). Against fairness. University of Chicago Press.

Atkinson, A. B., Piketty, T., \& Saez, E. (2011). Top incomes in the long run of history. Journal of Economic Literature, 49(1), 3-71

Benabou, R., \& Ok, E. A. (2001). Social mobility and the demand for redistribution: The POUM hypothesis. The Quarterly Journal of Economics, 116(2), 447-487

Choi, G. (2019). Revisiting the redistribution hypothesis with perceived inequality and redistributive preferences. European Journal of Political Economy, 58, 220-244

Cruces, G., Perez-Truglia, R., \& Tetaz, M. (2013). Biased perceptions of income distribution and preferences for redistribution: Evidence from a survey experiment. Journal of Public Economics, 98, 100-112

Dawes, C. T., Fowler, J. H., Johnson, T., McElreath, R., \& Smirnov, O. (2007). Egalitarian motives in humans. Nature, 446(7137), 794-796. https://doi.org/10.1038/nature05651

Deaton, A. (2013). The great escape: health, wealth, and the origins of inequality. Princeton University Press.

Eriksson, K., \& Simpson, B. (2012). What do Americans know about inequality? It depends on how you ask them. Judgment and Decision Making, 7, 741-745

Fehr, E., \& Schmidt, K. M. (1999). A theory of fairness, competition, and cooperation. The Quarterly Journal of Economics, 114(3), 817-868

Ferrer-i-Carbonell, A. (2005). Income and well-being: an empirical analysis of the comparison income effect. Journal of Public Economics, 89(5-6), 997-1019

Ferrer-i-Carbonell, A., \& Frijters, P. (2004). How important is methodology for the estimates of the determinants of happiness? The Economic Journal, 114(497), 641-659

Ferrer-i-Carbonell, A., \& Ramos, X. (2014). Inequality and happiness. Journal of Economic Surveys, 28(5), 1016-1027

Frederick, S., Loewenstein, G., \& O'donoghue, T. (2002). Time discounting and time preference: A critical review. Journal of economic literature, 40(2), 351-401

Gimpelson, V., \& Treisman, D. (2018). Misperceiving inequality. Economics \& Politics, 30(1), 27-54

Harsanyi, J. C. (1980). Can the maximin principle serve as a basis for morality? A critique of john rawls's theory essays on ethics, social behavior, and scientific explanation. (pp. 37-63). Springer.

Hirschman, A. O., \& Rothschild, M. (1973). The changing tolerance for income inequality in the course of economic development: With a mathematical appendix. The Quarterly Journal of Economics, 87(4), 544-566

Iacono, R., \& Ranaldi, M. (2021). The nexus between perceptions of inequality and preferences for redistribution. The Journal of Economic Inequality, 19, 97-114. https://doi.org/10.1007/s10888-020-09470-7

Kahneman, D., \& Riis, J. (2005). Living, and thinking about it: Two perspectives on life. In N. B. F. Huppert \& B. Keverne (Eds.), The science of well-being. (Vol. 1, pp. 285-304). Oxford University Press.

Kahneman, D., \& Tversky, A. (1979). Prospect theory: An analysis of decision under risk. Econometrica, 47, 263-291

Kiatpongsan, S., \& Norton, M. (2014). How much (more) should CEOs make? A universal desire for more equal pay. Perspectives on Psychological Science, 9(6), 587-593

Luttmer, E. F. P. (2005). Neighbors as negatives: Relative earnings and well-being. The Quarterly Journal of Economics, 120(3), 963-1002. https://doi.org/10.1093/qje/120.3.963 
Michels, A., \& De Graaf, L. (2010). Examining citizen participation: Local participatory policy making and democracy. Local Government Studies, 36(4), 477-491. https://doi.org/10.1080/03003930.2010. 494101

Morawetz, D., Atia, E., Bin-Nun, G., Felous, L., Gariplerden, Y., Harris, E., \& Zarfaty, Y. (1977). Income distribution and self-rated happiness: Some empirical evidence. The Economic Journal, 87(347), $511-522$

Norton, M. I., \& Ariely, D. (2011). Building a better America-one wealth quintile at a time. Perspectives on Psychological Science, 6(1), 9-12. https://doi.org/10.1177/1745691610393524

OECD. (2011). Divided we stand: Why inequality keeps rising. Paris: Organization of Economic Cooperation and Development.

OECD. (2015). In it together: Why less inequality benefits all. Paris: Organization for Economic Cooperation.

Oishi, S., \& Kesebir, S. (2015). Income inequality explains why economic growth does not always translate to an increase in happiness. Psychological Science, 26(10), 1630-1638. https://doi.org/10.1177/09567 97615596713

Palais, J. B. (1984). Confucianism and the aristocratic/bureaucratic balance in Korea. Harvard Journal of Asiatic Studies, 44(2), 427-468

Piketty, T., \& Saez, E. (2014). Inequality in the long run. Science, 344(6186), 838-843

Preacher, K. J., \& Hayes, A. F. (2004). SPSS and SAS procedures for estimating indirect effects in simple mediation models. Behavior Research Methods Instruments \& Computers, 36(4), 717-731

Putnam, R. D. (2000). Bowling alone: America's declining social capital culture and politics. (pp. 223234). Springer.

Rawls, J. (1971). A theory of justice. New york: Harvard University Press.

Sen, A. K. (1992). Inequality reexamined. Oxford University Press.

Sen, A. K. (1999). Development as freedom. Anchor Books.

Shaw, A., \& Olson, K. (2014). Fairness as partiality aversion: The development of procedural justice. Journal of Experimental Child Psychology, 119, 40-53

Shaw, A., \& Olson, K. R. (2012). Children discard a resource to avoid inequity. Journal of Experimental Psychology General, 141(2), 382-395. https://doi.org/10.1037/a0025907

Starmans, C., Sheskin, M., \& Bloom, P. (2017). Why people prefer unequal societies. Nature Human Behaviour, 1, 0082. https://doi.org/10.1038/s41562-017-0082

Xiao, E., \& Bicchieri, C. (2010). When equality trumps reciprocity. Journal of Economic Psychology, 31(3), $456-470$

Yang, Y., Onderstal, S., \& Schram, A. (2016). Inequity aversion revisited. Journal of Economic Psychology, $54,1-16$

Publisher's Note Springer Nature remains neutral with regard to jurisdictional claims in published maps and institutional affiliations. 